Supporting Information to

\title{
Adsorption of Alkanes in Zeolites LTA and FAU: Quasi- Equilibrated Thermodesorption Supported by \\ Molecular Simulations
}

by

Andrzej Sławek, José Manuel Vicent-Luna, Karolina Ogorzały, Susana Valencia, Fernando Rey, Wacław Makowski, and Sofía Calero 
The total energy of the system can be divided into bonded and non-bonded components:

$U^{\text {total }}=U^{\text {bonded }}+U^{\text {non-bonded }}$

Non-bonded component of the total energy consists of Lennard-Jones and electrostatic contributions:

$U^{\text {non-bonded }}=U^{L-J}+U^{\text {electrostatic }}$

Lennard-Jones (12-6) potential consists of attractive (van der Waals) and repulsive (Pauli exclusion principle) terms:

$U^{L-J}\left(r_{i j}\right)=4 \varepsilon_{i j}\left[\left(\frac{\sigma_{i j}}{r_{i j}}\right)^{12}-\left(\frac{\sigma_{i j}}{r_{i j}}\right)^{6}\right]$

Electrostatic interactions were calculated with Coulombic potential:

$U^{\text {electrostatic }}\left(r_{i j}\right)=\frac{1}{4 \pi \varepsilon_{0} \varepsilon_{r}} \frac{q_{i} q_{j}}{r_{i j}{ }^{2}}$

Table S1. Force field parameters for non-bonded interactions used in this work. ${ }^{1,2,3}$

Lennard-Jones parameters for guest-guest, guest-host, and guest-cations interactions. ${ }^{a}$

\begin{tabular}{ccccccccc}
\hline & $\mathrm{O}_{\mathrm{Al}}$ & $\mathrm{O}_{\mathrm{Si}}$ & $\mathrm{Na}^{+}$ & $\mathrm{Ca}^{2+}$ & $\mathrm{CH}_{3}$ & $\mathrm{CH}_{2}$ & $\mathrm{CH}$ & $\mathrm{C}$ \\
\hline \multirow{2}{*}{$\mathrm{Na}^{+}$} & 3.4 & 3.4 & - & - & 2.65 & 2.95 & 2.58 & 2.71 \\
& 23 & 23 & & - & 443.73 & 310 & 292 & 126 \\
$\mathrm{Ca}^{2+}$ & 3.45 & 3.45 & - & - & 2.6 & 2.8 & & - \\
& 18 & 18 & & & 400 & 440.73 & & \\
$\mathrm{CH}_{3}$ & 3.48 & 3.48 & 2.65 & 2.6 & 3.76 & 3.86 & 4.22 & 5.07 \\
& 93 & 93 & 443.73 & 400 & 108 & 77.77 & 42.85 & 9.3 \\
$\mathrm{CH}_{2}$ & 3.58 & 3.58 & 2.95 & 2.8 & 3.86 & 3.96 & 4.32 & 5.17 \\
& 60.5 & 60.5 & 310 & 440.73 & 77.77 & 56 & 30.85 & 6.69 \\
$\mathrm{CH}^{2}$ & 3.92 & 3.92 & 2.58 & & 4.22 & 4.32 & 4.67 & 5.53 \\
& 40 & 40 & 292 & - & 42.85 & 30.85 & 17 & 3.69 \\
$\mathrm{C}$ & 4.56 & 4.56 & 2.71 & - & 5.07 & 5.17 & 5.53 & 6.38 \\
& 10 & 10 & 126 & - & 9.3 & 6.69 & 3.69 & 0.8 \\
\hline
\end{tabular}

${ }^{\text {a }}$ where $\sigma[\AA]$ is the top entry, while $\varepsilon / \mathrm{k}_{\mathrm{B}}[\mathrm{K}]$ is the bottom entry.

Charges used for electrostatic interactions.

\begin{tabular}{ccccccc}
\hline & $\mathrm{O}_{\mathrm{Al}}{ }^{\mathrm{b}}$ & $\mathrm{O}_{\mathrm{Si}}{ }^{\mathrm{b}}$ & $\mathrm{Na}$ & $\mathrm{Ca}$ & $\mathrm{Si}$ & $\mathrm{Al}$ \\
\hline$q(\mathrm{e})$ & -1.2 & -1.025 & +1.00 & +2.00 & +2.05 & +1.75 \\
\hline
\end{tabular}

${ }^{\mathrm{b}} \mathrm{O}_{\mathrm{Al}}$ is oxygen atom bridging one silicon and one aluminum atom. $\mathrm{O}_{\mathrm{Si}}$ is oxygen atom bridging two silicon atoms. 
Bonded component of the total energy consist of bonding, bending and torsion components:

$U^{\text {bonded }}=U^{\text {bond }}+U^{\text {bend }}+U^{\text {torsion }}$

Table S2. Force field parameters for bonded interactions used in this work.

$$
\begin{aligned}
& U^{\text {bond }}\left(r_{i j}\right)=\frac{1}{2} k_{i j}\left(r_{i j}-r_{i j}^{0}\right)^{2} \\
& \mathrm{CH}_{x}-\mathrm{CH}_{x} \quad k_{i j} / k_{B}=96500 \mathrm{~K} / \AA^{2} \quad r_{i j}^{0}=1.54 \AA \quad \text { subscript } x=0,1,2 \text { or } 3 \\
& U^{\text {bend }}\left(\theta_{i j k}\right)=\frac{1}{2} k_{i j k}\left(\theta_{i j k}-\theta_{i j k}^{0}\right)^{2} \\
& \mathrm{CH}_{x}-\mathrm{CH}_{2}-\mathrm{CH}_{x} \quad k_{i j} / k_{B}=62500 \mathrm{~K} / \mathrm{rad}^{2} \vartheta_{i j \mathrm{k}}^{0}=114^{\circ} \quad \text { subscript } x=2 \text { or } 3 \\
& \mathrm{CH}_{x}-\mathrm{CH}-\mathrm{CH}_{x} \quad k_{i j} / k_{B}=62500 \mathrm{~K} / \mathrm{rad}^{2} \vartheta_{i j k}^{0}=112^{\circ} \quad \text { subscript } x=2 \text { or } 3 \\
& \mathrm{CH}_{x}-\mathrm{CH}-\mathrm{CH}_{x} \quad k_{i j} / k_{B}=62500 \mathrm{~K} / \mathrm{rad}^{2} \vartheta_{i j k}{ }^{0}=119.47^{\circ} \quad \text { subscript } x=2 \text { or } 3 \\
& U^{\text {torsion }}\left(\varphi_{i j k l}\right)=p_{0}+p_{1}\left[1+\cos \varphi_{i j k l}\right]+p_{2}\left[1-\cos 2 \varphi_{i j k l}\right]+p_{3}\left[1+\cos 3 \varphi_{i j k l}\right] \\
& \mathrm{CH}_{x}-\mathrm{CH}_{2}-\mathrm{CH}_{2}-\mathrm{CH}_{x} \quad p_{0} / k_{B}=0.0 \mathrm{~K} \quad p_{1} / k_{B}=335.03 \mathrm{~K} \quad \text { subscript } x=2 \text { or } 3 \\
& p_{2} / k_{B}=-68.19 K \quad p_{3} / k_{B}=791.32 K \\
& \mathrm{CH}_{x}-\mathrm{CH}-\mathrm{CH}_{y}-\mathrm{CH}_{x} \quad p_{0} / k_{B}=-251.06 \mathrm{~K} \quad p_{1} / k_{B}=428.73 \mathrm{~K} \quad \text { subscript } x=2 \text { or } 3 \\
& p_{2} / k_{B}=-111.85 K \quad p_{3} / k_{B}=441.27 K \quad \text { subscript } y=1 \text { or } 2 \\
& \mathrm{CH}_{3}-\mathrm{C}-\mathrm{CH}_{2}-\mathrm{CH}_{3} \quad p_{0} / k_{B}=0.0 \mathrm{~K} \quad p_{1} / k_{B}=0.0 \mathrm{~K} \quad \text { only for 22DMB } \\
& p_{2} / k_{B}=0.0 \mathrm{~K} \quad p_{3} / k_{B}=461.29 \mathrm{~K}
\end{aligned}
$$




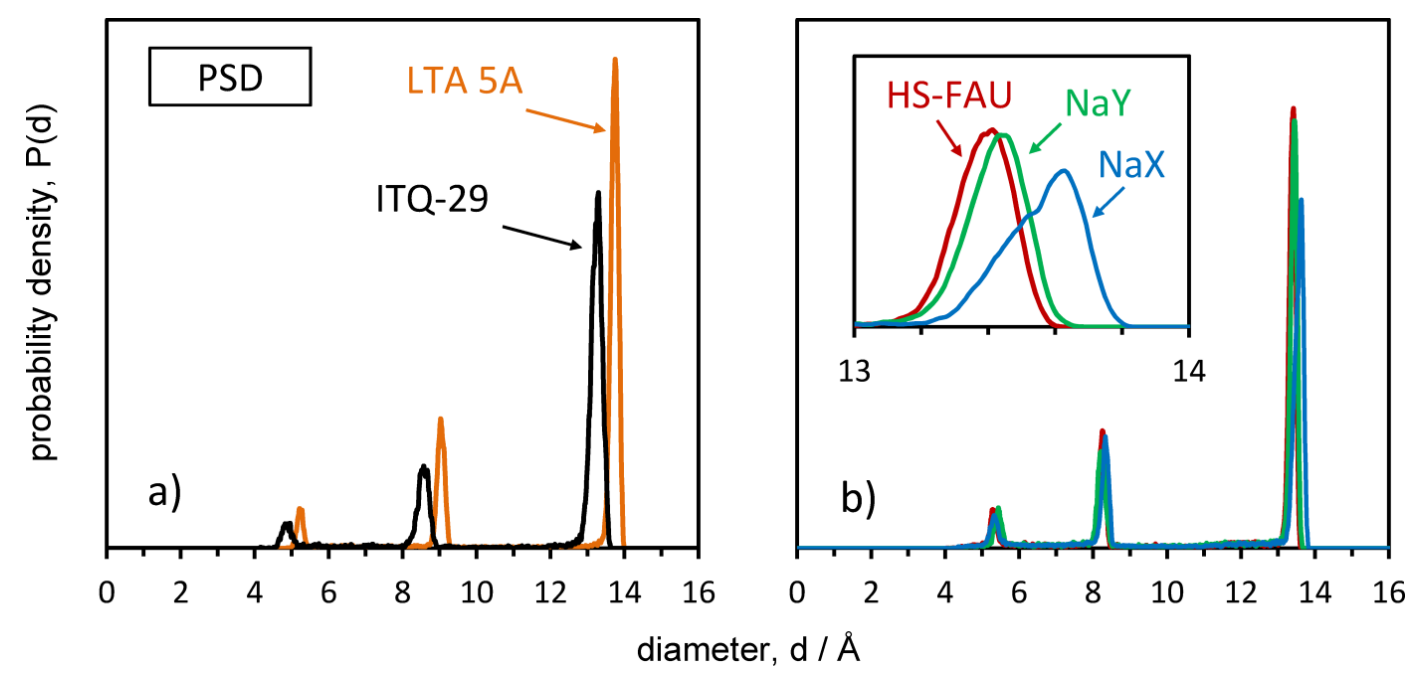

Figure S1. Pore size distribution of LTA (a) and FAU (b) zeolites under this study calculated geometrically using the method of Gelb and Gubbins. ${ }^{4,5}$
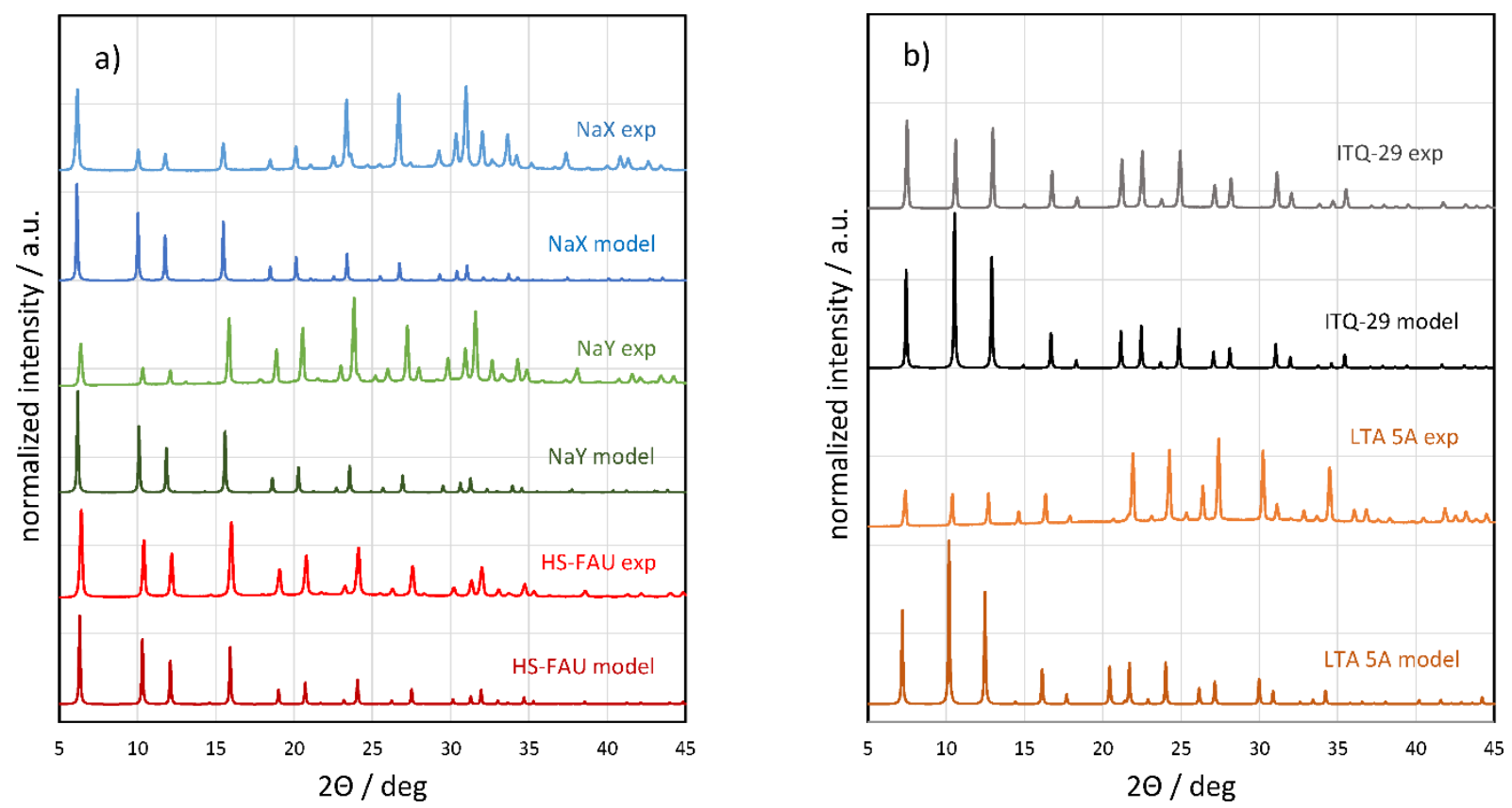

Figure S2. Comparison of the experimental and modelled XRD pattern of the studied zeolites FAU (a) and LTA (b). The modelled patterns were calculated from .cif files taken for molecular simulations. 

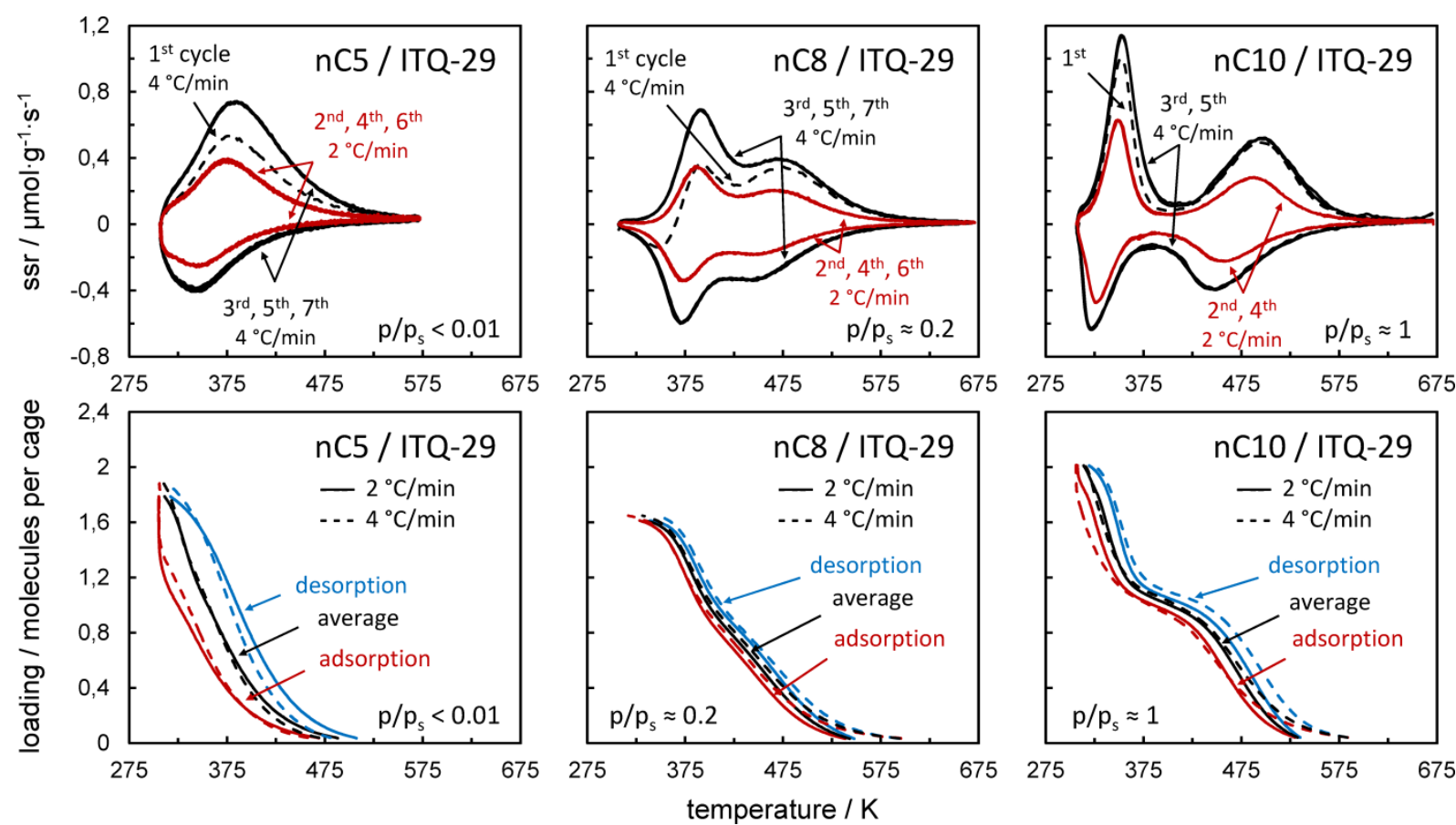

Figure S3. Top: The QE-TPDA profiles of $\mathrm{nC5}, \mathrm{nC8}, \mathrm{nC10}$ in ITQ-29. The dashed lines correspond to the first desorption cycle. Bottom: Corresponding adsorption isobars integrated from the profiles recorded with $2{ }^{\circ} \mathrm{C} / \mathrm{min}$ (solid lines) and $4^{\circ} \mathrm{C} / \mathrm{min}$ (dashed lines).
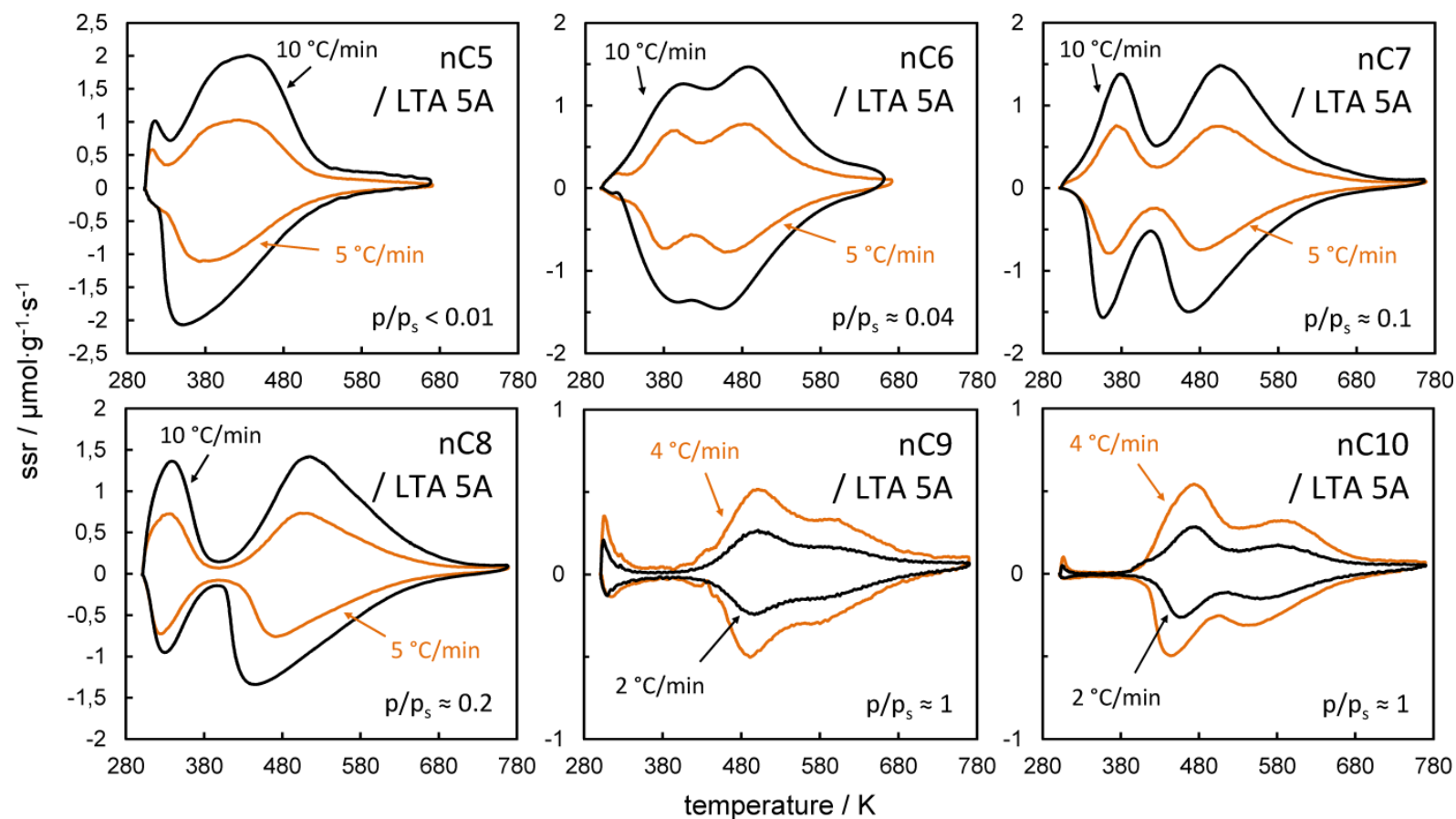

Figure S4. QE-TPDA profiles of $n$-alkanes LTA 5A (CaNa-LTA, Si/Al $=1$ ) recorded with heating/cooling rate of 10 and $5{ }^{\circ} \mathrm{C} / \mathrm{min}$ for $\mathrm{C} 5-\mathrm{C} 8$ or 4 and $2{ }^{\circ} \mathrm{C} / \mathrm{min}$ for $\mathrm{C} 9$ and $\mathrm{C} 10$. The values of pressures of the following $\mathrm{n}$-alkanes in the homologous series are 520,680,600, 310, 510, and $150 \mathrm{~Pa}$. 


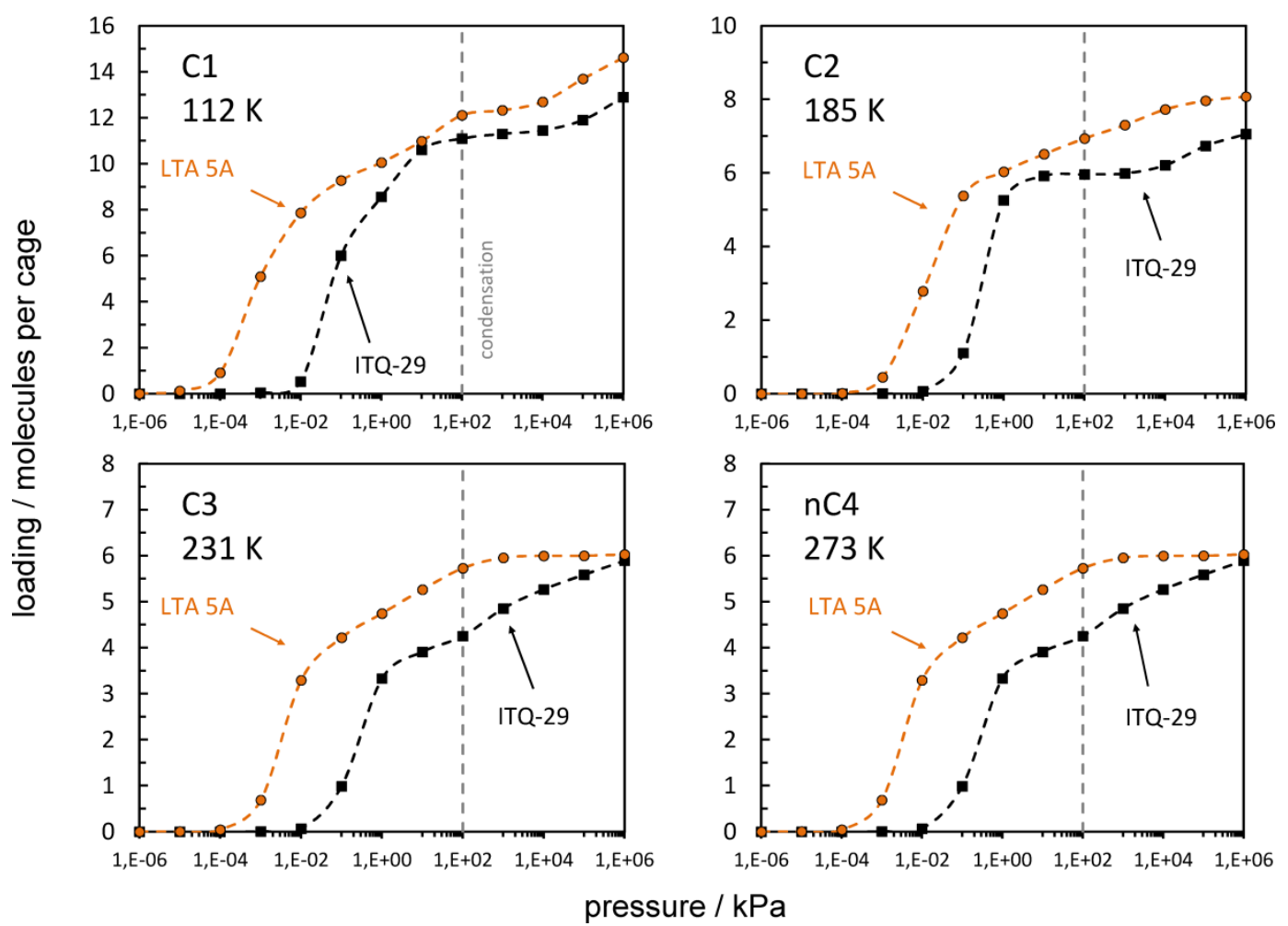

Figure S5. Adsorption isotherms of C1-C4 $n$-alkanes in ITQ-29 (black squares) and LTA 5A (orange circles) calculated for temperatures of condensation at standard pressure. Vertical dotted lines indicate the pressure of gas-liquid phase transition of pure adsorbates.

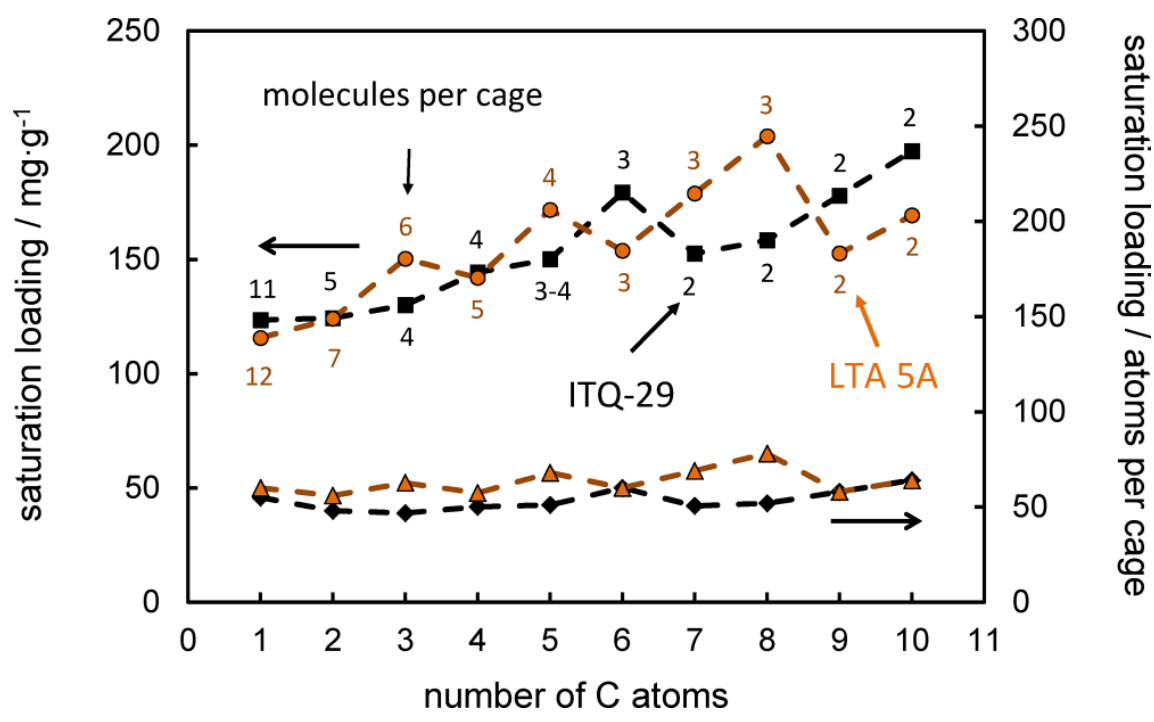

Figure S6. Sorption capacities of C1-C10 $n$-alkanes in ITQ-29 and LTA 5A zeolites expressed in mg/g (main y asis) and atoms/cage (auxiliary y asis). The values for $\mathrm{C} 1-\mathrm{C} 4$ are taken from adsorption isotherms shown in Figure $\mathbf{S} 4$ for condensation pressure $(100 \mathrm{kPa})$. The values for $\mathrm{C} 5-\mathrm{C} 10$ are taken from the adsorption isobars (Figure 5) for condensation temperature of 213, 233, 253, 273, 293, 313 $\mathrm{K}$ for the following $\mathrm{C} 5-\mathrm{C} 10 \mathrm{n}$-alkanes, respectively. Inset data labels stand for loading in molecules per cage units. 
Figure S6 reveals trend in the sorption capacities of C1-C10 $n$-alkanes in the studied LTA zeolites obtained from GCMC calculations. The lowest mass sorption capacity is observed for methane or ethane. On the one hand, small molecules are expected to fill most efficiently channels and cavities of the microporous frameworks. But on the other hand, they have the lowest molar contribution to the mass sorption capacity. For C3-C10 n-alkanes we observe fluctuations of mass saturation loading. Naturally, larger differences appear when long molecules reach their maximum filling of the pores (for 5A: nC8 - 3 molecules/cage, nC9- 2 molecules/cage). However, when expressed as total number of atoms per unit cage, the sorption capacities are fairly independent on the chain length. This indicates that the molecules of $n$-paraffins efficiently fill the pores within the LTA framework.

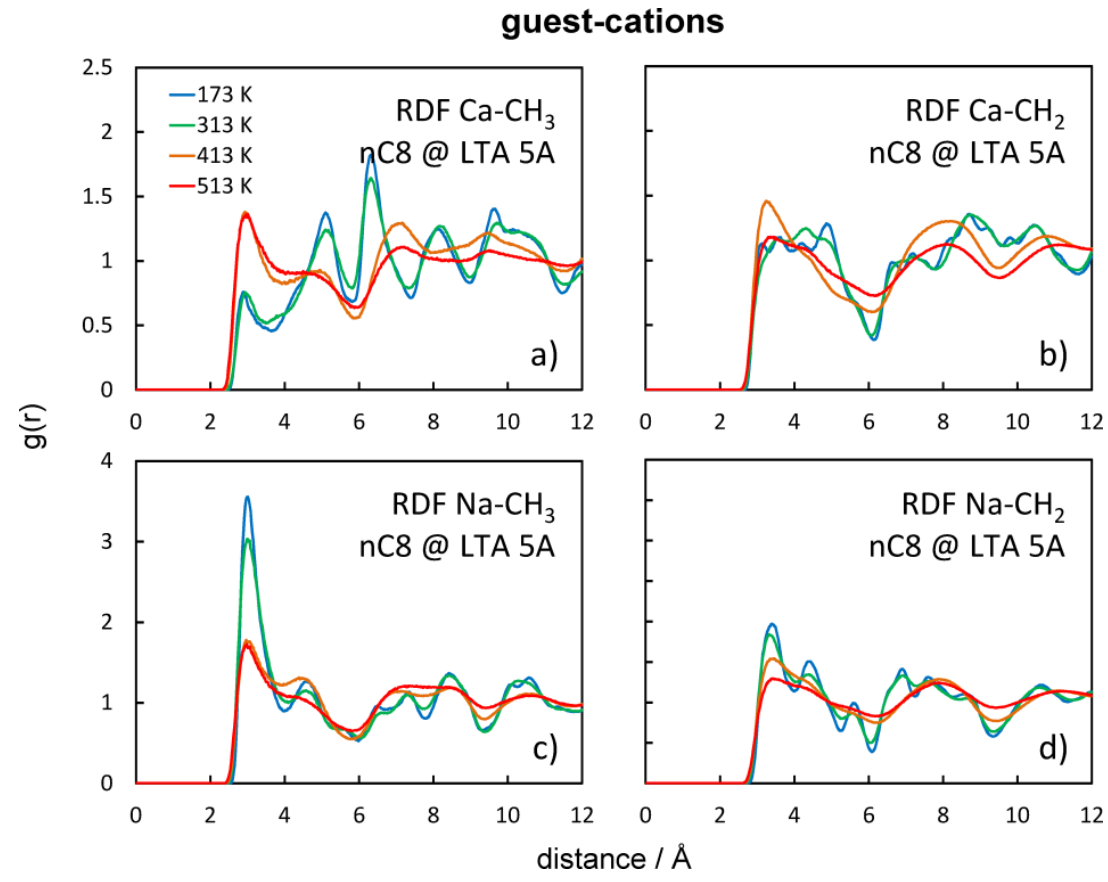

Figure S7. Radial distribution functions between $\mathrm{CH}_{3} / \mathrm{CH}_{2}$ pseudoatoms and extra-framework $\mathrm{Ca}^{2+}(\mathrm{a}$, b) and $\mathrm{Na}^{+}(\mathrm{c}, \mathrm{d})$ cations for adsorption of $n$-heptane in LTA 5A. Color lines stand for different temperatures: $173 \mathrm{~K}$ (blue), $313 \mathrm{~K}$ (green), $413 \mathrm{~K}$ (orange), and $513 \mathrm{~K}$ (red). Values of temperature of $173 \mathrm{~K}$, and $313 \mathrm{~K}$ correspond to the loading of 3 molec./u.c., $413 \mathrm{~K}$ to 2 molec./u.c., and $513 \mathrm{~K}$ to ca 1 molec./u.c. 


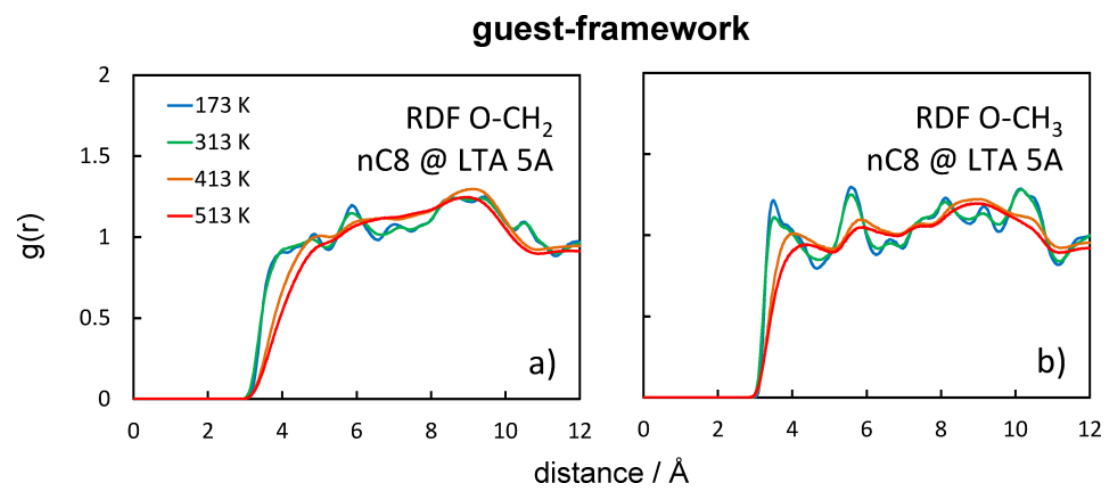

Figure 58. Radial distribution functions between $\mathrm{CH}_{3} / \mathrm{CH}_{2}$ pseudoatoms and framework $\mathrm{O}$ atoms for adsorption of $n$-heptane in LTA 5A. Color lines stand for different temperatures: $173 \mathrm{~K}$ (blue), $313 \mathrm{~K}$ (green), $413 \mathrm{~K}$ (orange), and $513 \mathrm{~K}$ (red). Values of temperature of $173 \mathrm{~K}$, and $313 \mathrm{~K}$ correspond to the loading of 3 molec./u.c., $413 \mathrm{~K}$ to 2 molec./u.c., and $513 \mathrm{~K}$ to ca $1 \mathrm{molec} . / \mathrm{u} . c$.
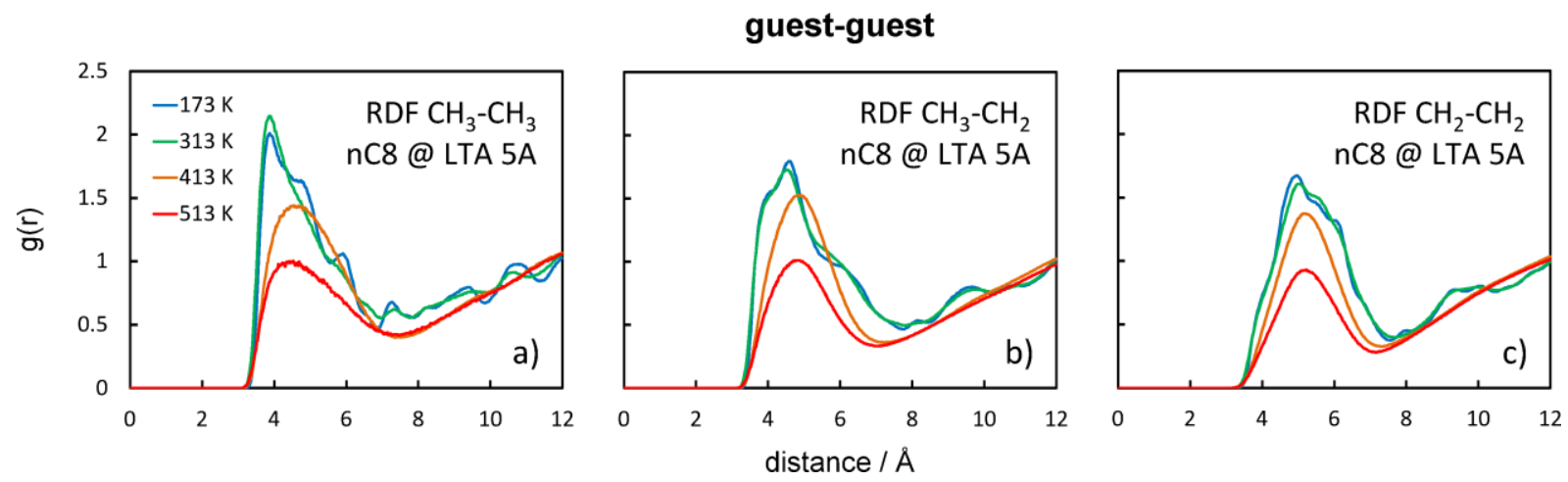

Figure 59. Radial distribution functions between $\mathrm{CH}_{3}-\mathrm{CH}_{3}$ (a), $\mathrm{CH}_{3}-\mathrm{CH}_{2}$ (b), and $\mathrm{CH}_{2}-\mathrm{CH}_{2}$ (c) pseudoatoms of $n$-heptane adsorbed in LTA 5A. Color lines stand for different temperatures: $173 \mathrm{~K}$ (blue), $313 \mathrm{~K}$ (green), $413 \mathrm{~K}$ (orange), and $513 \mathrm{~K}$ (red). Values of temperature of $173 \mathrm{~K}$, and $313 \mathrm{~K}$ correspond to the loading of 3 molec./u.c., $413 \mathrm{~K}$ to $2 \mathrm{molec} . / \mathrm{u} . c$. , and $513 \mathrm{~K}$ to ca $1 \mathrm{molec} . / \mathrm{u} . \mathrm{c}$. 


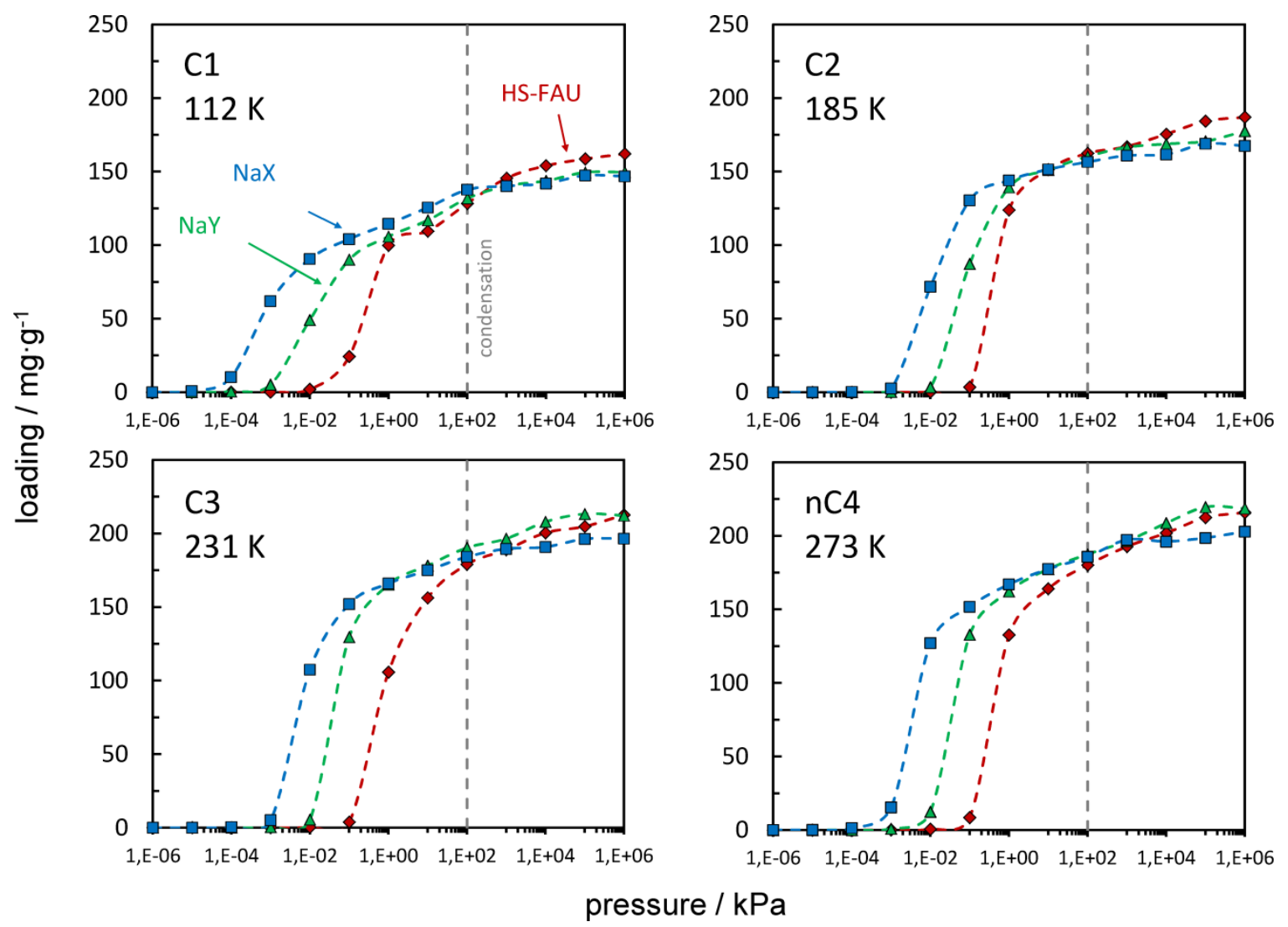

Figure S10. Adsorption isotherms of C1-C4 $n$-alkanes in high-silica Na-FAU (HS-FAU, red diamonds), $\mathrm{NaY}$ (green triangles), and $\mathrm{NaX}$ (blue squares) calculated for temperatures of condensation at standard pressure. Vertical dotted lines indicate the pressure of gas-liquid phase transition of pure adsorbates.
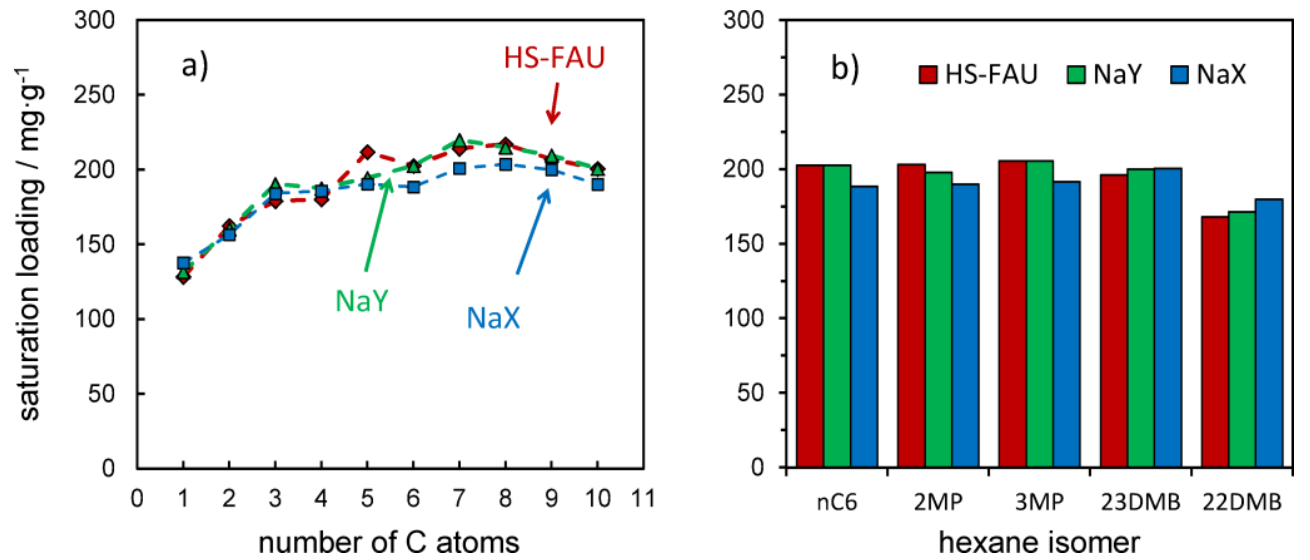

Figure S11. Sorption capacities of C1-C10 n-alkanes (a) and hexane isomers (b) in the studied faujasites obtained from GCMC calculations. The values for $\mathrm{C} 1-\mathrm{C} 4$ are taken from adsorption isotherms shown in Figure $\mathbf{S 9}$ for condensation pressure $(100 \mathrm{kPa})$. The values for $\mathrm{C} 5-\mathrm{C} 10$ are taken from the adsorption isobars (Figure 10, 11) for condensation temperature of 213, 233, 253, 273, 293, $313 \mathrm{~K}$ for the following $\mathrm{C} 5-\mathrm{C} 10 \mathrm{n}$-alkanes, respectively. 
In Figure S11a the relation between saturation loading and chain length of C1-C10 nalkanes is presented. Saturation loadings do not differ significantly for C3-C10 as they range from 180 to $220 \mathrm{mg} \cdot \mathrm{g}^{-1}$. Generally, sorption capacity slightly decreases with increasing cation content. Although the size of unit cell increases with $\mathrm{Na}^{+}$content (Table 1), some of the available pore volume is occupied by the cations. Similarly as for LTA-type zeolites, faujasites adsorb less methane or ethane than longer paraffins. In Figure S11b we presented the values of saturation loading for hexane isomers. Except of 22DMB, all C6 alkanes are adsorbed in similar quantities. Most probably this is due to the largest steric hindrance of the molecules of 22DMB which cannot be packed as effectively in the pores of FAU as molecules of other isomers. Radial distribution functions presented in Figure S12a show that more nC6 molecules are located closer to the framework atoms than the molecules of $22 \mathrm{DMB}$ as the first peak at ca $4 \AA$ is more intense. On the other hand, the second peak at ca $6 \AA$ is more intense for 22DMB. The adsorbed molecules of nC6 and 22DMB are located at a similar distance from each other (ca $4 \AA$ ), which is seen on radial distribution functions between $\mathrm{CH}_{3}$ groups of guest molecules (Figure 12b). However, since the 22DMB molecule has more $\mathrm{CH}_{3}$ groups than the $\mathrm{nC} 6$ molecule, the direct comparison between these radial distribution functions may not be completely reliable.
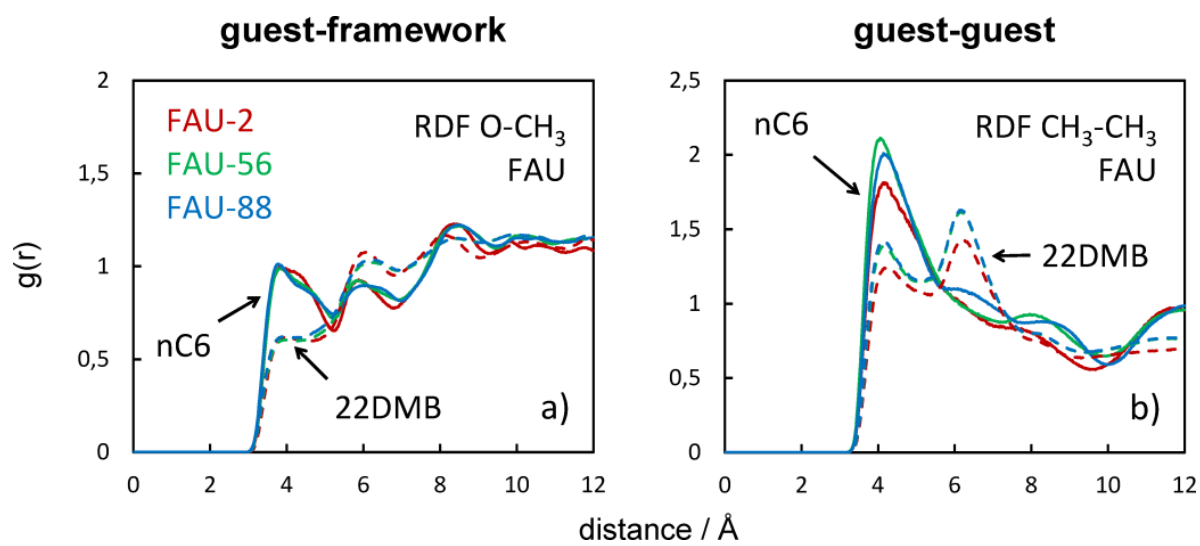

Figure S12. a) Radial distribution functions between $\mathrm{CH}_{3}$ pseudoatoms and framework $\mathrm{O}$ atoms for adsorption of $n$-hexane (solid lines) and 2,2-dimethylbutane (dashed lines) in FAU. b) Radial distribution functions between $\mathrm{CH}_{3}$ pseudoatoms of $n$-hexane (solid lines) and 2,2-dimethylbutane (dashed lines) adsorbed in FAU. Color lines stand for different cation content: FAU-2 (red), FAU-56 (green), FAU-88 (blue). Value of temperature of $233 \mathrm{~K}$ corresponds to the saturation conditions of the studied adsorbates. 


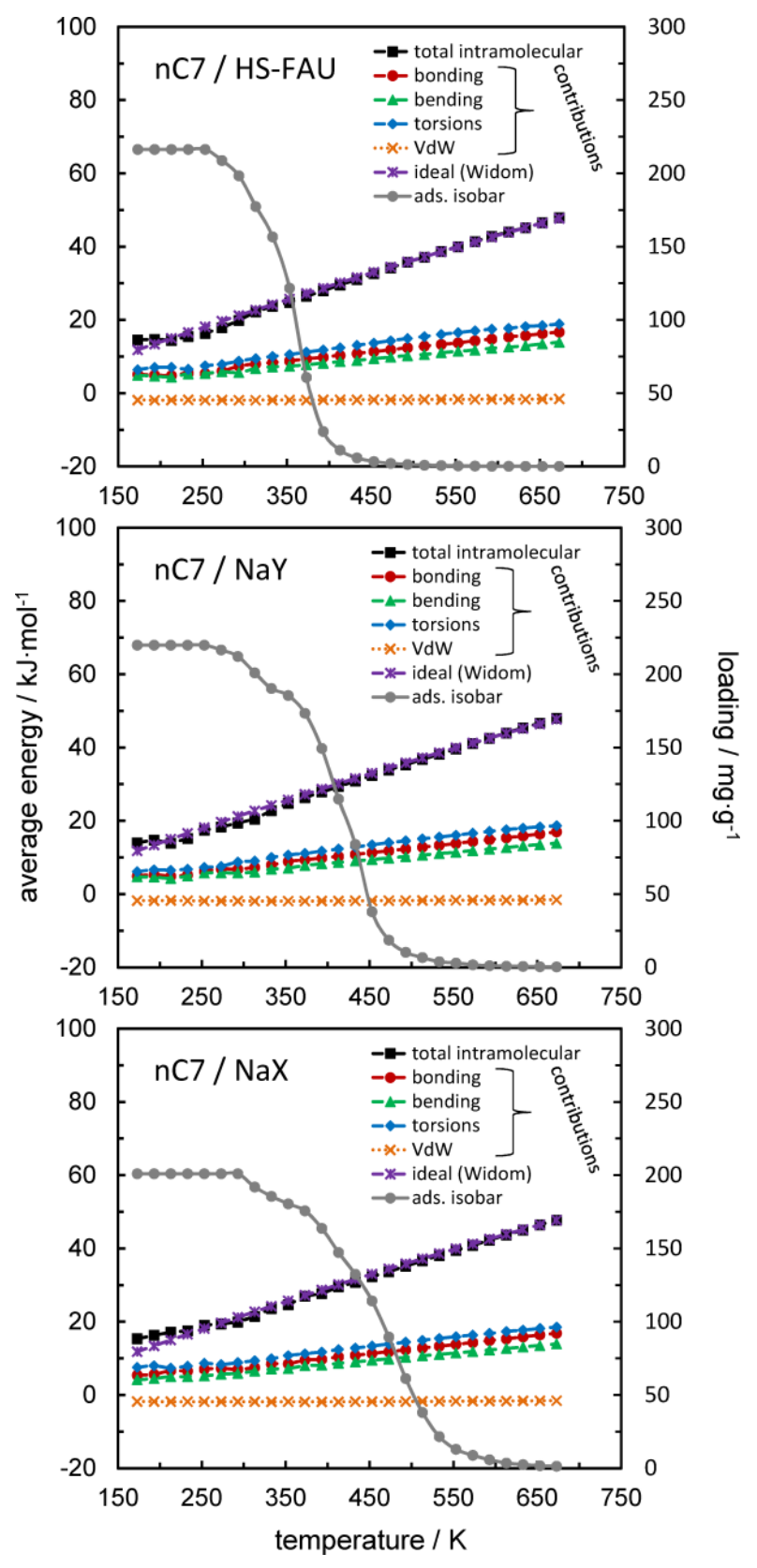

Figure S13. Contributions of bonding (red circles), bending (green triangles), torsion (blue diamonds), and long-range Van der Waals (orange crosses) interactions in intramolecular energy of $\mathrm{nC7}$ molecules adsorbed in FAU zeolites (black diamonds) compared to the energy for gaseous nC7 using the same model of the molecule (orange circles). Adsorption isobars were plotted on auxiliary axes as grey circles. 

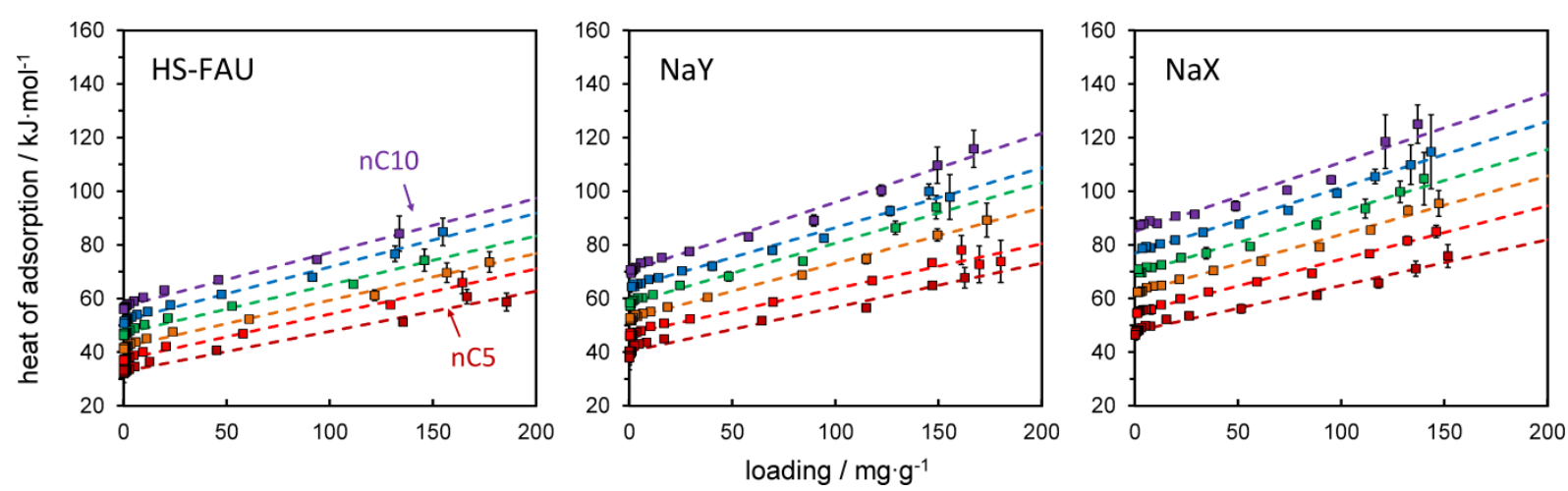

Figure S14. Isosteric heat of adsorption of $n$-alkanes in FAU zeolites calculated with GCMC. Linear trends were plotted with dashed lines.

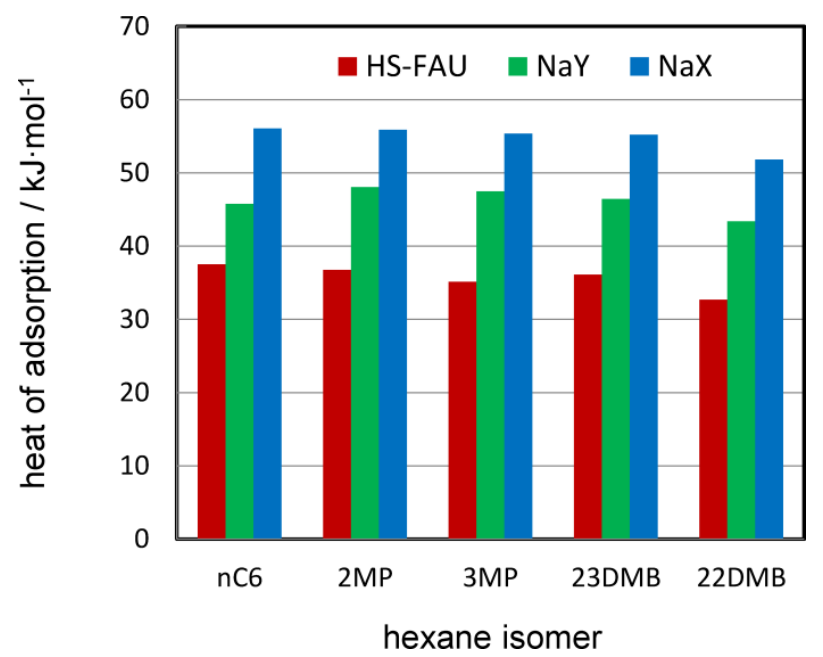

Figure S15. Low-coverage heat of adsorption of C6 isomers in FAU zeolites calculated with GCMC.

\section{Literature}

1. Dubbeldam, D.; Calero, S.; Vlugt, T. J. H.; Krishna, R.; Maesen, T. L. M.; Smit, B. United Atom Force Field for Alkanes in Nanoporous Materials. J. Phys. Chem. B 2004, 108, 12301-12313.

2. $\quad$ Calero, S.; Dubbeldam, D.; Krishna, R.; Smit, B.; Vlugt, T. J. H.; Denayer, J. F. M.; Martens, J. A.; Maesen, T. L. M. Understanding the Role of Sodium During Adsorption: A Force Field for Alkanes in Sodium-Exchanged Faujasites. J. Am. Chem. Soc. 2004, 126, 11377-11386.

3. Garcia-Perez, E.; Dubbeldam, D.; Maesen, T. L. M.; Calero, S. Influence of Cation $\mathrm{Na} / \mathrm{Ca}$ Ratio on Adsorption in LTA 5A: A Systematic Molecular Simulation Study of Alkane Chain Length. J. Phys. Chem. B 2006, 110, 23968-23976.

4. Gelb, L. D.; Gubbins, K. E. Pore Size Distributions in Porous Glasses: A Computer Simulation Study. Langmuir 1999, 15, 305-308.

5. Sarkisov, L.; Harrison, A. Computational Structure Characterisation Tools in Application to Ordered and Disordered Porous Materials. Mol. Simul. 2011, 37, 1248-1257.

6. NIST Chemistry WebBook. http://webbook.nist.gov/chemistry/ (accessed October 24, 2019) 